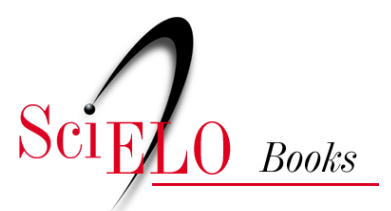

\title{
Palestra \\ Direitos e cidadania dos usuários de álcool e outras drogas
}

\author{
Antônio Lancetti
}

\section{SciELO Books / SciELO Livros / SciELO Libros}

LANCETTI, A. Direitos e cidadania dos usuários de álcool e outras drogas. In: BARROS, S., BATISTA, L.E., and SANTOS, J.C., comps. Saúde mental e reabilitação psicossocial: avanços e desafios nos 15 anos da Lei 10.2016 [online]. Uberlândia: Navegando Publicações, 2019, pp. 143-149. ISBN: 978-6581417-07-9. https://doi.org/10.7476/9786581417079.0009. Transcrição dos Anais do II Encontro de Saúde Mental - Reabilitação Psicossocial: avanços e desafios 15 anos após a Lei 10.216, Uberlândia, MG, 2016.

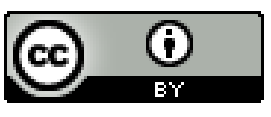

All the contents of this work, except where otherwise noted, is licensed under a Creative Commons Attribution 4.0 $\underline{\text { International license. }}$

Todo o conteúdo deste trabalho, exceto quando houver ressalva, é publicado sob a licença Creative Commons Atribição 4.0.

Todo el contenido de esta obra, excepto donde se indique lo contrario, está bajo licencia de la licencia $\underline{\text { Creative }}$ Commons Reconocimento 4.0 . 


\section{Palestra - Direitos e cidadania dos usuários de álcool e outras drogas}

Coordenação: Profa . Dra. Paula Hayasi Pinho - Psicóloga, Pós-doutoranda na da Escola de Enfermagem da USP.

\section{Dr. Antônio Lancetti}

Psicanalista, Consultor do Programa de Saúde Mental de São Bernardo do Campo, Ex-Secretário de Ação Comunitária no município de Santos, Ex-consultor do Ministério da Saúde para o Plano Crack.

(Cumprimenta os organizadores, amigos e plateia)

Então esse sujeito sem direitos, que depois escreveu outro livro chamado Homo Sacer, era aquele sobre o qual se poderia fazer qualquer coisa, por que aquele sujeito não tinha desejo, não tinha palavra, muito menos direitos, o livro se chama "O que sobrou de Auschwitz" e depois escreveu isso que nós usamos hoje tão coerentemente que é a história das “ilhas de exceção", Então, eu fui supervisor das equipes de saúde da família desde 2009, aqui na cracolândia paulistana e todo tipo de abuso foi cometido com essas pessoas, desde PMs apostando, com estilingue, quem acertava mais nóias, com bolinhas de gude, internações involuntárias, programas que definem (tenho um colega que diz assim, ele tem um livro chamado O Usuário de Crack, vocês já viram a capa, ele é quase assim, para bom entendedor meia palavra basta, e ele diz que o cara que o uso continuo de crack é uma doença crônica, recidivante que nãoprecisa do consentimento do paciente para ser tratado).

Bom, com esse critério se criou o Programa Recomeço, primeiro estabiliza, depois interna para sociabilizar e fica curado, se bem que eles conseguiram convencer muitos agentes comunitários, mas eles depois vieram assim desanimados por que quase todos eles voltaram para a zona de uso, quando não para as cadeias, então, como para nós o problema da cidadania tem sido essencial? O Guattari disse que o Basaglia, ele elevou ao status ontológico o conceito de cidadania, o que significa isso? Que quando você bate o 
olho no paciente, você fala, "esse sujeito, primeiro, é um cidadão" e depois, "é um paranoico, é um dependente químico ou uma histérica". Então, nós fizemos uma das maiores reformas psiquiátricas, porque aqui se comemoram quinze anos, no mundo, baseada no conceito de cidadania que se traduz assim: "Por uma utopia de uma sociedade sem manicômios".

Utopia mais ou menos, por que em Santos, (eu tenho colegas aqui a Sandra Chioro, que? E ainda eu e Andrea, que foram protagonistas, não sei se tem mais gente, e que não foi uma utopia. Lá, nós transformamos uma cidade média, pequena-média, numa sociedade sem manicômio. Santos foi a primeira cidade brasileira sem manicômios. $\mathrm{O}$ Guattari falou (Andrea é testemunha, foi uma boa conversa), que lá aconteceu a quarta revolução psiquiátrica, não é verdade? Então, nós estávamos indo bem. Vivendo em um Brasil amoroso, fazendo grupos, festas, até que nos lançaram a campanha da Epidemia do Crack e, nós que já sabíamos tratar de esquizofrênicos, e não foi nada fácil, nos pegaram de calças curtas. E muita gente se atrapalhou e nós tentamos muitas coisas. Eu participei do Plano Crack, com a capacitação da polícia comunitária, eu acho que o Plano Crack, que do ponto de vista midiático foi ruim, ele funcionou. O plano crack foi acompanhado de uma extensão da rede de cuidados, porque o Tykanori e o Leon quando estavam no Ministério eles falavam: "a gente não pode matar o crack, nem

o craqueiro, mas a gente pode oferecer uma rede de cuidado". E essa rede foi criada e não foi nada fácil, primeiro, porque (escrevi um livro chamado "Contrafissura" com um problema maior, que tem cada técnico que atende usuários de drogas e quer salvá-los e acham que uma pessoa pode ficar em abstinência, ou acha que pode atender também da mesma maneira como atendem os outros. E... então, muitos CAPS álcool e drogas põem agendas, não atendem as prioridades. Aqui que eu posso falar entre amigos, certo? Agora, o Denis é testemunha que lá em Guarulhos, uma administração progressista tinha muitos problemas para atender drogados.

Enfim, então, além desses problemas, que acho que todo mundo padeceu, eu quando descobri o primeiro menino usuário de crack, em Santos, peguei ele, com o meu carro, e fui para a praça da Independência peguei ele no braço e levei para o pronto socorro. E não perguntei se ele queria ou não queria e ele, "não quero". "Você não é minha mãe para me levar" e eu, "não sou sua mãe, não sou seu pai". Então, nós fomos (lembro que o livro, que a gente escreveu nos últimos dias de governo em Santos se chamava Assistência Social e Cidadania e o capítulo sobre os usuários - porque chegou o crack em Santos e de uma hora para outra e tudo mudou - então, o capítulo se chamava "Crack: endurecer sem perder a ternura”. Fizemos de passagem, a nossa pequena homenagem ao 
comandante. Então, nós temos criado redes, incluindo pessoas das UBS, mobilizando... o grande exemplo é em São Bernardo, tem alguém de São Bernardo? Só você? O dia que se faça a história da saúde mental brasileira e do trabalho com usuários de drogas, vão ter que pendurar um quadrinho com a foto do CAPS Ad de São Bernardo do Campo, e o CAPS Ad também, que passou muitos perrengues mas, porque foram precursores do que é trabalhar em rede, porque foram precursores do que é se superar a cada momento, porque não é qualquer sujeito que consegue tratar de usuários que são verdadeiros toxicômanos, miseráveis, pessoas com longas vidas passadas nas cadeias e nas clínicas de recuperação. Então, nós temos feito esse esforço, não temos avançado muito, sabemos que agora está em um momento muito difícil, e eu acho que o grande destaque que devemos fazer é o programa De Braços Abertos.

O Programa de Braços Abertos, eu não sei se aqui foi comentado ou vocês o conhecem, mas ele tem uma ideia inicial, junta com algumas ideias iniciais, a primeira é que ele foi inspirado em um programa americano e é justo aqui fazer (porque a gente falava assim "o que vamos fazer de diferente? PSF tem. Mal. Porque funcionava muito mal aqui, porque achavam que PACS de rua era a mesma coisa que consultório na rua. Nós temos serviços de saúde que de alguma maneira funcionam com alguma conexão, porque durante esses dois anos anteriores cada um chutava para um lado, e os agentes comunitários quando levavam um paciente ao Pronto Socorro eram humilhados junto com os pacientes, e a assistente social trabalhando empurrando pessoas, e a guarda municipal jogavam gás de pimenta por uma lei aprovada na Câmara dos Vereadores desta cidade aqui pertinho, e apoiado por $90 \%$ da população paulistana. E, o Tykanori ligou para o Saraceno e o Saraceno disse, "olha, a única coisa nova que tem é housing first". Housing first é uma invenção americana que depois se aperfeiçoou no Canadá e em outros lugares, que consiste em dar primeiro casa, porque o psicólogo Sam Tsemberis, que parece que foi o primeiro que começou a pensar nisso, se cansou de levar a pessoa para as comunidades terapêuticas e a clínicas de recuperação e as prisões, levavam para lá e perguntavam, "quem é que está falando"? Voltavam para a zona de uso e para o mesmo buraco, ele teve essa ideia, só que nem ele mesmo acreditava na ideia, e um ano depois ele verificou que $84 \%$ das pessoas ainda estavam nos hotéis, claro que não é nada fácil. Aqui que tem uma profissional que coordena os hotéis aqui da região e sabe que é um turbilhão, mas está escrevendo sobre essa loucura, o capítulo sobre o Braços Abertos, deveria se chamar "hotéis dos braços abertos: os turbilhões". E, foi bom, uma longa discussão, com muita paciência, porque, engraçado, porque nem o projeto Qualis quando a gente inventou, de Saúde Mental com a equipe volante sem CAPS e sem ambulatório, a gente sofreu ataque de todos os lugares, a começaram pela direita e logo após, pela esquerda. 
O Davi, me lembro uma vez que foi convidado para falar aqui, na Câmara, e falei que se não fosse um amigo, eu achava que aquilo era uma armadilha, porque me bateram tanto, quando fui explicar como funcionava, que os agentes de saúde e os enfermeiros e os médicos iam para a casa da pessoa. O único que nos apoiou foi... alguns loucos como sempre e o professor Adib Jatene, porque quando eu contei para ele, o que fazíamos, ele disse "olha Lancetti, tenho cinquenta anos de experiência clínica, o que um médico sabe em seu consultório se comparado a uma visita domiciliar?". Então aquilo lá, nem é nosso companheiro, mas com o Braços Abertos aconteceu isso. As pessoas nas reuniões, quem coordenava as reuniões era o Sottili, que era secretário de direitos humanos, ia lá para criticar que não tinha dados, que a guarda municipal era pior que a PM, mas nós acabamos de criar uma inspetoria especial para redução de danos para a guarda municipal, nós capacitamos esses guardas para serem intermediadores, as pessoas nos hotéis bancam as crises que eles tem, porque nós ainda somos de uma geração ou de várias gerações que acreditamos que uma pessoa pode mudar.

Então, o Programa de Braços Abertos, realmente, depois de todas essas discussões, lançou, foi muito interessante, o Programa de Braços Abertos começou dia 14 de janeiro de 2014... 2013... 2014, na reunião (eu vou ter que sair correndo daqui, porque essa foi à primeira, agora, vai ter a última reunião (eu deveria estar às três lá, eu vou chegar atrasado, eu já cheguei aqui, vocês também estavam). A gente lançou no dia 14, na reunião com o prefeito estava tudo pronto para lançar no dia 15 e ai, eu falei uma coisa que não vou repetir aqui que não vai dar tempo, mas é, eu falei "prefeito, não pode ser no dia 15" (que a gente aprende, efetivamente, aprendemos em Santos o fator surpresa)... dia 13... 15 não pode ser, por que dia 15 vão entrar os holofotes, vão estar um monte de mídias lá, nós temos que falar um dia e fazer outro e foi fantástico, por que no dia anterior já estavam conversando, o pessoal do consultório na rua, que ainda não era, mas já se chamavam e as assistentes sociais, e ai quando explicaram que eles iriam negociar... Tudo bem compadre?(Cumprimenta Paulo Amarante, que entra no auditório) - Ele vem acompanhado de um grande antropólogo. E ai, porque havia uma favela na Rua Silva Bueno, e os holofotes, as fotos, a mídia inteira falando da favela, agora não tem favela, agora terminou, mas tinha a favela e tal, então foi negociado que se eles levantaram a favela... E ai, ele falou, eu montei meu barraco, eu vou desmontar, e ai começou a desmontar, nem todos foram desmontados por ele, mas a iniciativa foi deles, e foi assim como foi feita a primeira reintegração de posse no centro da cidade de São Paulo, sem bombas de gás lacrimogêneo, sem pauladas, com esse grupo de pessoas que são as piores, piores no sentido de "cidadania consiste em tomar o direito mais difícil, é o mais complicado". 
Muito bem, e assim foi como começou o programa De Braços Abertos dando o que nós chamávamos de "um pacote de direitos": dormir, comer e trabalhar. E, nós estivemos, (eu vejo isso nas suposições) sem o ânimo de... nós adotamos o conceito da redução de danos, mas nós tivemos que reinventar o conceito da redução de danos, porque a redução de danos como feita em São Bernardo ou em Aracaju ou em Recife, é diferente de como é feita aqui. Aqui, o grau de tensão que tem com os traficantes, com a polícia, com os tráficos diversos, e toda hora vira o problema, quando parece que a coisa está se arranjando a polícia prende o chefe do tráfico de chamado "disciplina" e fica sem chefe e ai vira uma balburdia e o consultório na rua não consegue chegar lá. Esse é um dos problemas, outro é a visibilidade, que tem os projetos, tanto é que apesar da Folha de São Paulo verificar que 69\% dos paulistanos apoiam o projeto De braços abertos, o candidato ganhador se elegeu com a ideia de que os braços estão abertos para... a morte e tudo isso, porque, claro, isso dá medo, todo sujeito tem medo.

Eu sou psicanalista e não conheço um paciente que não tenha a fantasia de dormir embaixo da ponte, inclusive o mais rico. O medo de ser tocado por um sujeito estranho, sujo e ainda que tenha a coisa fascinante de usar uma droga, que se você usar uma vez, não consegue parar mais. Então, é aquela mistura, senão, não teria tantos religiosos, tantos antropólogos, tantos, enfim, pessoas de todos os tipos querendo resgatar, enfim, eu acho que merece esse trato especial porque com o decorrer do tempo nós... primeiro, outra característica do programa é que ele é intersecretarial, ele não é de uma secretaria, ele não exige, seria o ânimo de insultar nossos ânimos. Nós devemos reinventar-nos. Não só pela violência, porque, bom, a primeira coisa que aprendemos, isso tanto aqui como no CAPS, que trabalha de portas abertas de verdade, é.... a baixa exigência, que muita gente entende por não fazer nada, ou deixar que a coisa corra solta, ela é acompanhada de uma altíssima exigência do operador, do cuidador. Perguntem as pessoas que trabalham nos hotéis ou favelas, vão ver como não é fácil permanecer lá, ou quem está na rua há muitos anos, né, como a companheira. Mas, enfim, altíssima exigência, quanto mais exigência significa baixo limiar de acesso, lá o trecho que significa baixo limiar de acesso e disparo, ou seja, o cara não precisa estar abstinente para participar, mas você injeta algumas drogas pesadas nele, por exemplo, o sujeito dorme, como eles falam, "com os dois olhos".

Nós fizemos um ato no Tuca, na terça-feira, e eu como tive um problema de saúde e faz tempo que não vou na cracolândia por problema de imunidade, perguntei para vários usuários “e, eu já sei que você dorme com os dois olhos, mas você sonha?", vai ele e fala, "muito mais". Mas o pior foi o Zé de Abreu, que é o nosso mentor, eu falei, 
“Zé, quando você estava na rua, você sonhava mais ou você sonhava menos?". Ele falou, "não, quando eu estava na rua eu sonhava muitos sonhos, agora é que eu sonho menos". "Como assim?". "Eu tenho sonhos repetitivos" (eu achei que eram sonhos traumáticos)," eu só sonho em como fazer para que essas pessoas saiam daqui, eu só sonho projeto de vida, meu e dos outros". Então, eu queria lembrar que o prefeito Doria, que ainda não é prefeito (é futuro), vai tirar o nome: De braços abertos. E nós como fomos derrotados, vamos ter que aguentar. Mas, será o quê? Porque esse nome foi tirado pelos usuários, com muita paciência democrática que cada vez que chamava para a assembleia, a polícia ficava na porta do ponto de apoio lá chamado Tenda, então, os usuários não queriam ir, lógico, foram ganhando confiança, foram discutindo o projeto, faz parte da metodologia do trabalho (não é que vai deixar para que eles resolvam tudo, que a gente também não é trouxa, certo?). Tem que ter comando, tem que ter escuta, então, quando tirem o nome De Braços Abertos, vão tirando um pedaço da alma do projeto. Eles já estão falando que, estão duvidando, que os hotéis vão fechar, por que? Porque estão vendo os resultados. Mais de 70\% excluída... coisa é difícil, vai dar um antibiótico ou atividade, para depressão geral dos trabalhadores de saúde.

Quanto trabalho eu tive? Que porcentagem? Mais de 70\%, e ainda de lambuja as pessoas consomem muito menos drogas, se você tem que acordar de manhã consome menos drogas que quando você não tem que acordar de manhã, e também por que se você dorme (parece tão evidente) que para tirar um cara da rua precisa dar uma casa e no entanto, aquilo que ficou uma espécie de revolução coopernicana ... hoje se uma pessoa rouba se fala, "não ele não rouba, ele tem que ir para o abrigo, ele pega cadeia", você não imagina que ele teria que ir para uma casa, embora seja uma coisa mais básica. Então, esses conceitos foram levados e isso trouxe muitos benefícios para a rede de Saúde Mental eu trabalhei em rede, tem pessoas aqui do CAPS que tiveram que quebrar a cabeça com esses casos mais complicados, ele obrigou a pessoa a sair da casinha, cada um de sua secretaria e produziu muitas surpresas, a gente não esperava que houvesse essa redução de consumo, a gente não esperava que muitas pessoas já nas primeiras semanas saíssem do local, isso ai eu chamei de segundo disparo, pois o primeiro disparo é essa condição: Caps que não funciona, você dorme em uma cama recolhido ou com medo que te joguem em um local deprimente. Aqui no CAPS do Bom Retiro de vez em quando aparecia paciente na AMA, especialmente negros e gays, com marcas da cruz suástica. Vocês fazem “ahhhh”, mas o médico achava normal, porque se o cara foi lá dormir no Baixo Augusta onde tem os carecas, e ele ainda é gay e preto... Então, olha só, o Saraceno na conferência que fez no Tuca, ele falou que esse passo, se começar com o direito, esse passo em vez de pedir para o cara parar de usar ou fazer xixi uma vez por semana 
no vidro, era uma forma de outorgar a cidadania. Não é que essa cidadania parou, por exemplo, hoje, a maioria dos usuários tem documentos. Olgaria Mattos me ensinou assim, que cidadania se entende assim, quando o PM te para e fala assim, "cidadão, você tem documento?". Então, não é só pelo documento, eu acho que essa é uma das maneiras de outorgar cidadania, de produzir, por que a gente não dá, a gente produz.

Bom, eu acho que nós temos um campo muito complexo no mundo, você recebe notícias de todo tipo, tem estados americanos que liberam o uso recreativo da maconha, está comprovado, está comprovado que tudo isso é muito mais caro, manter a pessoa pressa é muito mais caro muito mais ineficiente, então nós vamos sair daqui defendendo a eficácia desse projeto, mas veja, não depende de ideologia, depende da inteligência, por que se vocês vão querer fazer o que já fizeram, fazer procissões na madrugada de nóias, prendê-los, obrigá-los a se internar por que se não o cara vai preso, vocês vão fracassar, então nós deixamos um presente para a cidade, não sei se é um presente, mas deixamos um valor para a cidade, nós deixamos uma possibilidade de continuidade para os próximos gestores e vamos defender a sua continuidade. Mas nesse momento de tanta hipocrisia, de tanto, de algum modo falando de corporativismo. Bom, eu já tenho problemas de saúde, eu tenho uma certa facilidade para vomitar, não me custou muito, bom, mas enfim, nesses momentos, eu acho que nós perdemos muitas eleições e o pior é que nos roubaram os sonhos. Muitos ficaram culpados, principalmente os petistas, que ficam na dúvida, de dizer se roubou ou não roubou, é simples, eu acho que agora, no nosso coração antimanicomial, lhes dizer, "veja, perdemos as eleições aqui com braços abertos e com a rede que a gente construiu e com todo esforço que a gente tem feito e dizer veja tudo bem, agora vocês que vão gestar, mas os princípios ficam com a gente".

Obrigado. 